\title{
Polyoxometalate catalyzed ozonation of chemical pulps in organic solvent media
}

\author{
Anatoly A. Shatalov*, Helena Pereira \\ Centro de Estudos Florestais, Universidade Técnica de Lisboa, Instituto Superior de Agronomia, Tapada da Ajuda, 1349-017 Lisboa, Portugal
}

\section{A R T I C L E I N F O}

\section{Article history:}

Received 25 May 2009

Received in revised form 13 July 2009

Accepted 24 July 2009

\section{Keywords:}

Polyoxometalate

Heteropolyanion

Ozone

Ozone bleaching

Organic solvent

Eucalypt kraft pulp

\begin{abstract}
A B S T R A C T
Polyoxometalate (POM) catalyzed ozonation of chemical pulps in organic solvent media was found to be particularly effective and selective environmentally benign bleaching approach providing a way for substantial increase in pulp brightness, viscosity and degree of delignification in comparison with other ozone-based bleaching techniques. A series of tested low-boiling polar aprotic and protic organic solvents showed a well-defined capacity for ozonation improvement in the presence of Keggin-type heteropolyanion $\left[\mathrm{PMo}_{7} \mathrm{~V}_{5} \mathrm{O}_{40}\right]^{8-}$ (HPA-5). Even moderate solvent proportion of $6 \%(\mathrm{w} / \mathrm{w})$ in the reaction solution caused additional gain in brightness up to $3.4 \%$ ISO with simultaneous increase in pulp viscosity up to $8.8 \%$ and lignin removal up to $18.9 \%$ after HPA-5 catalyzed ozonation $\left(0.8 \% \mathrm{O}_{3} ; 0.5 \mathrm{mM} \mathrm{HPA}\right)$, as compared with the control solvent-free process. An aqueous acetone solution was found to be the preferred reaction medium in terms of pulp brightening and delignification. Under optimized conditions, the POM-catalyzed ozonation of eucalypt kraft pulp in acetone/water solution showed remarkable brightness improvement by $15.1 \%$ ISO with additional lignin removal by $39.4 \%$ and increase in intrinsic viscosity by $3 \%$ in comparison with pulp bleached in water media.
\end{abstract}

(c) 2009 Elsevier B.V. All rights reserved.

\section{Introduction}

Early transition metal oxygen anion clusters (polyoxometalates or POMs) find a wide application as versatile green catalysts for liquid-phase oxidation of different organic substances $[1,2]$. Heteropolyoxometalates (free heteropolyacids and salts of heteropolyanions) possessing the properties both of strong acids and of very efficient oxidants hold a great interest now for application as bi-functional catalysts in homogeneous and heterogeneous systems [3-5]. Remarkable features of heteropolyanions (HPAs) such as a high solubility in water and oxygen containing organic solvents, a high stability over a wide temperature and $\mathrm{pH}$ range and an ability of easy regeneration (re-oxidation) by molecular dioxygen, hydrogen peroxide and ozone have opened up new possibilities for HPAs utilization as efficient catalysts for environmentally benign (chlorine-free) selective delignification of lignocellulosics [6-8]. Continuous reuse (recirculation) of catalytic solution in a close-loop mode opens the possibility for development of totally effluentfree POM bleaching technology with carbon dioxide and water as the only byproducts after lignin oxidation [6]. The $\alpha$-Keggintype mixed-addenda HPAs, such as molybdovanadophosphate heteropolyanions of the series $\left[\mathrm{PMo}_{(12-n)} \mathrm{V}_{n} \mathrm{O}_{40}\right]^{(3+n)-}$, were recognized as the more suitable POMs for oxygen bleaching of chemical pulps [9]. The heteropolyanion $\left[\mathrm{PMo}_{7} \mathrm{~V}_{5} \mathrm{O}_{40}\right]^{8-}$ or HPA5 showed the best results in terms of delignification. However, the

\footnotetext{
* Corresponding author. Tel.: +351 21 3634662; fax: +351 213645000 . E-mail address: anatoly@isa.utl.pt (A.A. Shatalov).
}

high acidity of the reaction media ( $\mathrm{pH} \mathrm{1-2)} \mathrm{required} \mathrm{for} \mathrm{optimal}$ catalytic action of HPA- 5 affects negatively the carbohydrate complex of bleached pulp, causing undesirable hydrolytic (solvolytic) polysaccharide degradation and respective loss in pulp viscosity [10,11].

The low $\mathrm{pH}$ of reaction media limits the HPA-5 application for oxygen delignification, but makes it very attractive for ozone bleaching operating under the same acidic $\mathrm{pH}$ range. In HPAcatalyzed bleaching, the extremely high oxidation potential of ozone can substantially reduce the redox cycle of catalyst regeneration in comparison with oxygen or peroxide delignification, thereby providing an accelerated rate of bleaching reactions and a higher efficiency of the bleaching process as a whole.

Ozone is the most powerful and particularly potential oxidation agent in pulp bleaching technology [12]. The ozone bleaching stage, as an integrated part of the advanced totally chlorine-free (TCF) bleaching sequences, was recently applied to different types of conventional (sulfur-based) and unconventional (organosolv) pulps from a wide variety of woods and non-wood (agro-fibre) sources [13-15]. Despite the extremely high reactivity of ozone (oxidizing potential of $+2.07 \mathrm{eV}$ [16]), a low selectivity of ozone treatment towards lignin (due to unwanted reactions with cellulose leading to a deterioration of pulp quality) restricts the delignification capacity of ozone and limits its application in pulp bleaching technology as a whole. A variety of different chemicals, so-called "cellulose protectors", has been tested as the additives for reaction solution with an aim to improve ozonation performance. The positive effect of some organic solvents on pulp ozonation has been reported [17-20]. 
The selectivity improving of ozone bleaching still remains to be solved in spite of intensive efforts mounted in this field in the last two decades. The change in redox properties of oxidation bleaching system by application of POM catalysis can be a feasible way to increase selectivity and efficiency of pulp ozonation.

Early experiments on HPA-5 catalyzed ozone bleaching in aqueous medium showed promising results in terms of delignification [9], but the substantial loss in pulp viscosity was also revealed, indicating low suppression of radical-induced polysaccharide degradation.

The development of a novel particularly effective and selective pulp bleaching approach using POM-catalyzed ozonation in organic solvents as a reaction media is reported in the present paper. The effect of organic solvent and process variables on ozonation results and POM catalysis is discussed.

\section{Materials and methods}

\subsection{Materials}

Industrial unbleached eucalypt (E. globulus L.) kraft pulp (Portucel Mill) with $41.60 \pm 0.05 \%$ ISO brightness, $2.39 \pm 0.03 \%$ residual lignin (as Klason and acid-soluble) and an intrinsic viscosity of $1320 \pm 2 \mathrm{mLg}^{-1}$ was used. Before bleaching, the pulp was thoroughly washed with deionized water to remove all residual black liquor.

Molybdovanadophosphate heteropolyanion HPA-5 was prepared by stoichiometric reaction of $\mathrm{MoO}_{3}, \mathrm{~V}_{2} \mathrm{O}_{5}, \mathrm{NaH}_{2} \mathrm{PO}_{4}$ and $\mathrm{Na}_{2} \mathrm{CO}_{3}$ according to a previously described procedure [21].

Organic solvents as well as all other chemicals used were of analytical grade purity and purchased by Sigma-Aldrich, Riedel-de Haen and Fluka companies.

\subsection{Ozonation of kraft pulp}

Pulp ozonation ( $3 \%$ consistency; $0.8 \%$ ozone charge; $\mathrm{pH} 2 ; 20^{\circ} \mathrm{C}$ ) was performed in a $1 \mathrm{~L}$ Fischer glass batch reactor equipped with a high-speed teflon-covered stirrer and connected with a laboratory Fischer-502 ozone generator. After ozonation, pulps were thoroughly washed with deionized water. Acidic pulp treatment with diluted sulfuric acid ( $\mathrm{pH} 2 ; 30 \mathrm{~min}$ ) was performed before ozonation to increase ozone selectivity towards lignin. Ozone concentration was measured using a conventional iodometric procedure. Two replicated ozonation were performed for each experimental condition set.

\subsection{Pulp analysis}

Residual lignin content was determined as Klason and acidsoluble lignin according to T 222 om-88 and UM 250 TAPPI standards. Pulp viscosity was measured in cupri-ethylenediamine (CED) solution according to SCAN-CM 15:88 standard. Handsheet formation for physical and reflectance test was performed according to TAPPI T 205 om-88 and TAPPI T 272 om-92 standards, respectively. Physical properties of pulp hand-sheets were examined according to TAPPI T 220 om-88 standard. Pulp optical properties (ISO brightness and DIN $6167 \mathrm{C} / 2$ yellowness index) were measured by CM-3630 Spectrophotometer (Minolta).

The content of aldehyde (CHO) groups in pulps was measured spectroscopically at $546 \mathrm{~nm}$ (Shimadzu, UV-160A) after color reaction with 2,3,5-triphenyltetrazolium chloride [22].

Hexenuronic acid (HexA) groups in pulps were quantified by selective hydrolysis in formic acid-sodium formate buffer followed by UV-spectroscopy (Shimadzu, UV-160A) of the formed 2-furoic acid at $245 \mathrm{~nm}$ [23].
All measurements were replicated to obtain reproducible data.

Having in mind the economical and technological feasibility of possible chemicals recovery, a few low-boiling polar aprotic (acetone and dioxan) and protic (methanol, ethanol, $n$-propanol and isopropanol) organic solvents were chosen as a potential reaction media for POM-catalyzed ozone bleaching of chemical pulps.

\section{Results}

For solvent screening experiments, the industrial eucalypt ( $E$. globulus) kraft pulp was ozonated under fixed conditions of ozone charge and catalyst (HPA-5) concentration in the presence of 6\% (by weight) of organic solvent. The brightness development as well as the extent of lignin and carbohydrate degradation during ozonation was examined and compared with control (solvent-free) test.

\subsection{Comparative effect of different organic solvents on POM-catalyzed ozonation}

As can be seen from Table 1, the conventional ozonation in water media (control test) is fairly effective in delignification and brightness development of eucalypt kraft pulp. But, the substantial drop in pulp viscosity (by 30.3\%) with respective loss in pulp strength properties (expressed as tear, burst and tensile strength) is also observed, indicating intensive carbohydrate degradation.

The presence of POM (HPA-5) catalyst in aqueous solution has a positive effect on the selectivity of pulp ozonation (see control vs. POM/water, Table 1 ), by somewhat decreasing residual lignin and increasing pulp viscosity. But the pulp brightness, as the most important bleaching property, is only slightly affected.

It is evident from Table 1, that the addition of organic solvent into the reaction mixture substantially improves POM-catalyzed ozonation. Even a moderate solvent proportion of $6 \%(w / w)$ in aqueous solution caused a gain in brightness with simultaneous increase in pulp viscosity and lignin removal in comparison with POM/water and, particularly, with control (water, catalyst-free) ozonation.

Obviously, the bleaching effect depends on the nature of the organic solvent used. The comparative response of pulp to ozone treatment in different reaction media is shown in Figs. 1-3. Four tested solvent-based reaction systems (i.e., methanol-, ethanol-,

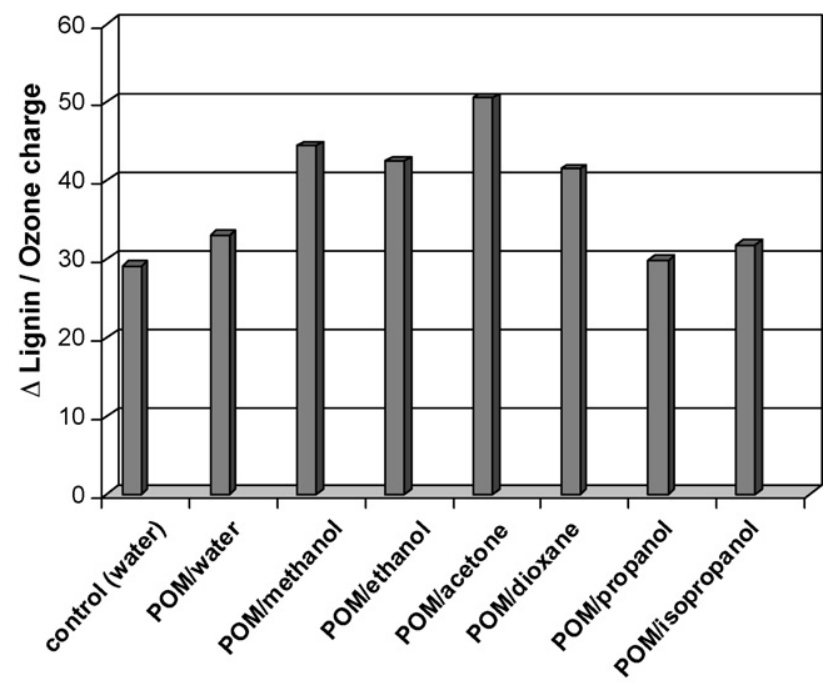

Fig. 1. Delignification efficiency of POM-catalyzed pulp ozonation in various reaction media (expressed as lignin decrease per unit of ozone applied). Ozonation conditions: $3 \%$ pulp consistency; $\left[\mathrm{O}_{3}\right]=0.8 \%$ odp; $[\mathrm{HPA}-5]=0.5 \mathrm{mM} ; 6 \%(\mathrm{w} / \mathrm{w})$ solvent concentration; $\mathrm{pH}=2$. 
Table 1

Results of HPA-5 catalyzed ozonation of eucalypt (E. globulus L.) kraft pulp in organic solvent/water reaction media ( $3 \%$ pulp consistency; $\left[\mathrm{O}_{3}\right]=0.8 \%$ odp $;$; $[\mathrm{HPA}-5]=0.5 \mathrm{mM} ; 6 \%$ ( $\left.\mathrm{w} / \mathrm{w}\right)$ solvent concentration; $\mathrm{pH}=2$ )

\begin{tabular}{|c|c|c|c|c|c|c|c|c|c|}
\hline Medium composition & $\begin{array}{l}\text { Brightness } \\
\text { (\%ISO) }\end{array}$ & $\begin{array}{l}\text { Yellowness } \\
\text { index }\end{array}$ & $\begin{array}{l}\text { Residual lignin } \\
\text { (\%odp) }\end{array}$ & $\begin{array}{l}\text { Intrinsic viscosity } \\
(\mathrm{ml} / \mathrm{g})\end{array}$ & HexA $(\mu \mathrm{mol} / \mathrm{g})$ & $\mathrm{CHO}(\mathrm{mmol} / 100 \mathrm{~g})$ & $\begin{array}{l}\text { Tear index } \\
\left(\mathrm{mN} \mathrm{m}^{2} / \mathrm{g}\right)\end{array}$ & $\begin{array}{l}\text { Burst index } \\
\left(\mathrm{kPa} \mathrm{m}^{2} / \mathrm{g}\right)\end{array}$ & $\begin{array}{l}\text { Tensile index } \\
(\mathrm{N} \mathrm{m} / \mathrm{g})\end{array}$ \\
\hline Control ozonation (water) & $53.2 \pm 0.06$ & $28.4 \pm 0.02$ & $1.83 \pm 0.01$ & $920 \pm 2$ & $14.88 \pm 0.08^{\mathrm{b}}$ & $11.12 \pm 0.04^{\mathrm{c}}$ & $3.86 \pm 0.07$ & $0.12 \pm 0.02$ & $3.02 \pm 0.06$ \\
\hline POM/water & $53.4 \pm 0.03$ & $28.3 \pm 0.03$ & $1.75 \pm 0.04$ & $951 \pm 1$ & $21.53 \pm 0.10$ & $8.80 \pm 0.05$ & $4.14 \pm 0.09$ & $0.15 \pm 0.01$ & $3.51 \pm 0.08$ \\
\hline $\mathrm{POM} /$ water/methanol & $55.8 \pm 0.05$ & $26.9 \pm 0.03$ & $1.54 \pm 0.02$ & $970 \pm 2$ & $17.44 \pm 0.11$ & $7.08 \pm 0.02$ & $4.43 \pm 0.06$ & $0.16 \pm 0.02$ & $3.98 \pm 0.09$ \\
\hline POM/water/ethanol & $55.2 \pm 0.03$ & $27.1 \pm 0.02$ & $1.58 \pm 0.03$ & $1035 \pm 3$ & $19.46 \pm 0.09$ & $7.53 \pm 0.01$ & $4.43 \pm 0.07$ & $0.15 \pm 0.03$ & $4.21 \pm 0.07$ \\
\hline $\mathrm{POM} /$ water/acetone & $56.8 \pm 0.05$ & $26.3 \pm 0.04$ & $1.42 \pm 0.01$ & $950 \pm 1$ & $17.10 \pm 0.04$ & $8.40 \pm 0.03$ & $4.16 \pm 0.11$ & $0.18 \pm 0.03$ & $4.58 \pm 0.12$ \\
\hline POM/water/dioxane & $55.8 \pm 0.08$ & $26.9 \pm 0.02$ & $1.59 \pm 0.02$ & $1026 \pm 2$ & $17.35 \pm 0.08$ & $6.60 \pm 0.06$ & $4.52 \pm 0.10$ & $0.21 \pm 0.01$ & $4.44 \pm 0.08$ \\
\hline POM/water/1-propanol & $54.1 \pm 0.03$ & $28.0 \pm 0.04$ & $1.81 \pm 0.04$ & $1028 \pm 2$ & $19.91 \pm 0.06$ & $6.72 \pm 0.05$ & $4.27 \pm 0.09$ & $0.19 \pm 0.03$ & $4.08 \pm 0.06$ \\
\hline POM/water/isopropanol & $51.7 \pm 0.03$ & $29.6 \pm 0.03$ & $1.78 \pm 0.03$ & $1017 \pm 1$ & $24.35 \pm 0.10$ & $7.44 \pm 0.03$ & $4.08 \pm 0.06$ & $0.17 \pm 0.03$ & $4.31 \pm 0.06$ \\
\hline Water/ethanol & $53.7 \pm 0.04$ & $28.0 \pm 0.03$ & $1.79 \pm 0.01$ & $995 \pm 2$ & $19.05 \pm 0.07$ & $8.30 \pm 0.04$ & $4.23 \pm 0.08$ & $0.15 \pm 0.01$ & $3.85 \pm 0.07$ \\
\hline Untreated pulp ${ }^{d}$ & $41.6 \pm 0.04$ & $35.5 \pm 0.02$ & $2.39 \pm 0.04$ & $1320 \pm 3$ & $45.88 \pm 0.09$ & $0.97 \pm 0.01$ & $4.08 \pm 0.08$ & $0.20 \pm 0.02$ & $4.68 \pm 0.10$ \\
\hline
\end{tabular}

a Ozone charge, \% on oven-dry pulp.

b $\mu$ mol of hexenuronic acid (HexA) groups per gram of oven-dry pulp.

c mmol of aldehyde (CHO) groups per $100 \mathrm{~g}$ of oven-dry pulp.

d Properties of initial untreated (unbleached) eucalypt kraft pulp.

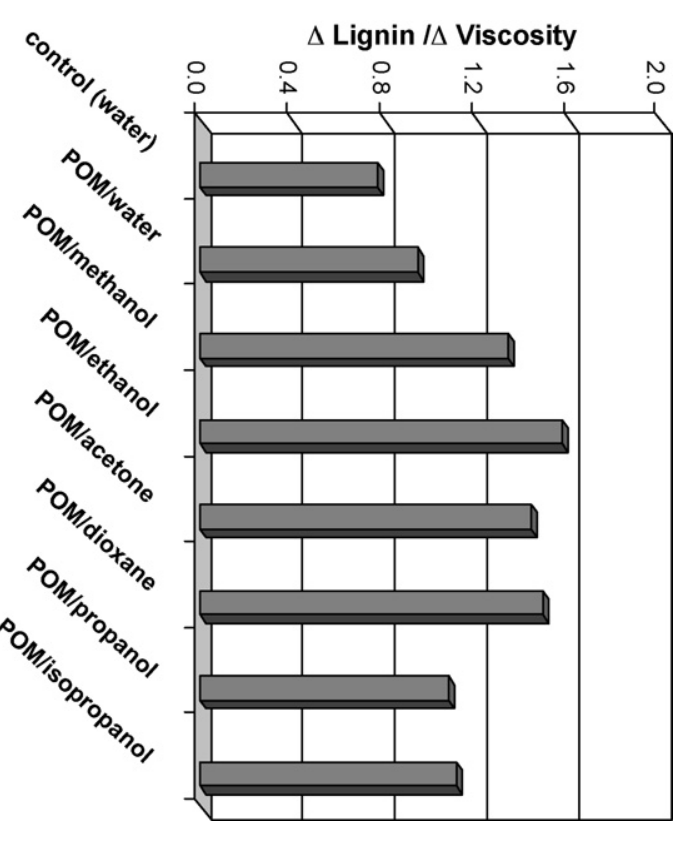

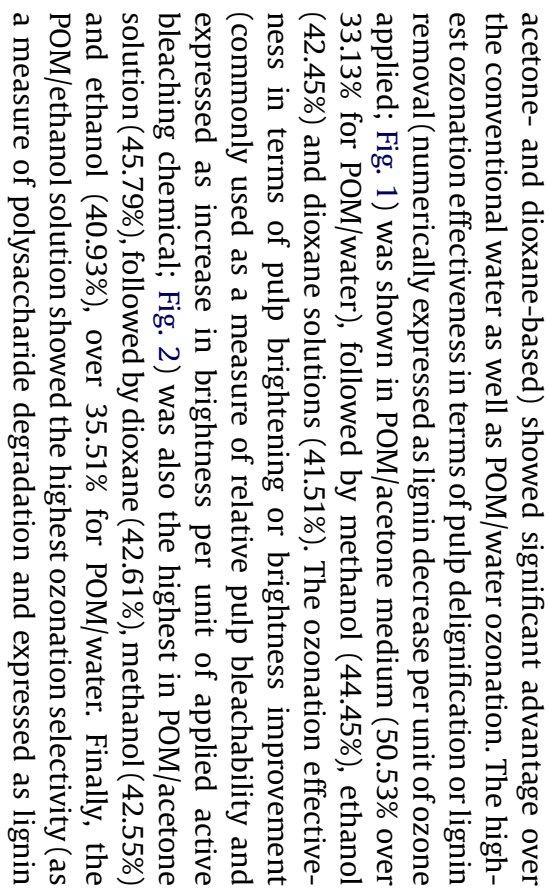

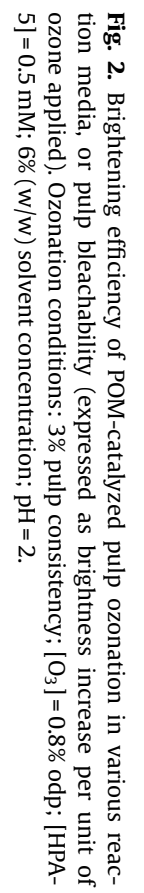

$\Delta$ Brightness / Ozone charge

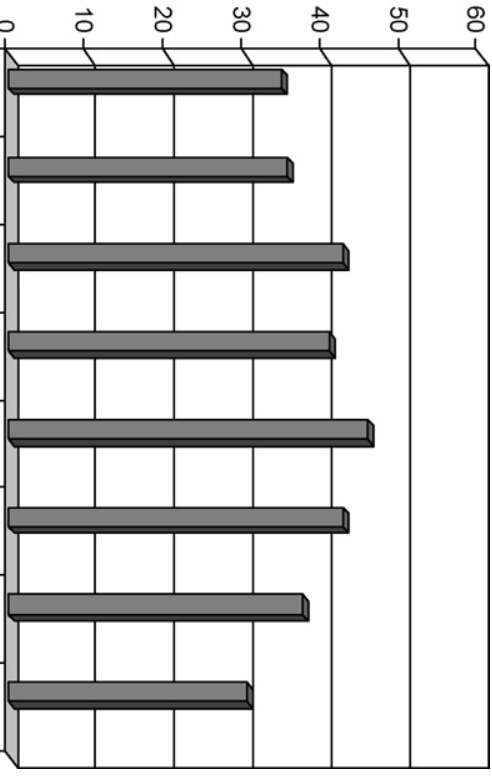


decrease per unit of viscosity decrease; Fig. 3), followed by dioxane, acetone and methanol solutions. The ozonation results in $n$-propanol and isopropanol solutions were somewhat poorer and comparable with solvent-free (POM/water) system.

Improved pulp viscosity in solvent-based ozonation systems is a result of carbohydrate protection against oxidative degradation due to scavenging by solvent of active radical species (basically hydroxyl and perhydroxyl radicals) [24] formed after direct ozone decomposition or indirectly by the reaction of ozone with lignin $[12,25]$. Since the carbohydrate degradation during ozonation results from the formation of oxidized functional groups such as carbonyl [26], the content of aldehyde ( $\mathrm{CHO}$ ) groups in ozonated pulp can indicate the degree of polysaccharide oxidative degradation. As can be seen from Table 1, the conventional ozonation in water (control ozonation) causes intensive pulp oxidation, increasing $\mathrm{CHO}$ content from $0.97 \mathrm{mmol}$ to $11.12 \mathrm{mmol}$ per $100 \mathrm{~g}$ of treated pulp. The presence of POM inhibits oxidation reactions leading to decrease in $\mathrm{CHO}$ groups by about $20 \%$ in comparison with control, presumably due to reported radical scavenging capacity of HPAs [27]. In POM/solvent media, the $\mathrm{CHO}$ content of ozonated pulps is $4.5-25 \%$ less than in $\mathrm{POM} /$ water and $24-40 \%$ less than in control (catalyst-free/water) ozonation, indicating substantial suppression of radical-induced carbohydrate degradation. Among the tested solvents, the highest degree of pulp oxidation was detected in $\mathrm{POM} /$ acetone ( $\mathrm{CHO}$ of $8.40 \mathrm{mmol}$ per $100 \mathrm{~g}$ of pulp) and the lowest in POM/dioxane media (CHO of $6.60 \mathrm{mmol}$ per $100 \mathrm{~g}$ of pulp).

The importance of pulp viscosity as a measure of carbohydrate preservation lies in its capacity to predict the strength properties and, eventually, the practical usability (and, sometimes, the suitability as a whole) of tested pulps. As evident from Table 1, the elevated intrinsic viscosity of pulps ozonated in POM/solvent media is directly related with their better strength properties. The tearing, bursting and tensile indexes of these pulps are notably higher than those found for control (water) and POM/water ozonation and near the strength indexes of untreated (unbleached) pulp.

The POM catalysis has some effect on hexenuronic acids (HexA) of ozonated pulps (Table 1 ). HexA (4-deoxy- $\beta$-L-threo-hex4-enopyranosyluronic acid) is formed from 4-O-methylglucuronic acid side-groups of hemicellulosic heteroxylan during alkaline pulping of lignocellulosics [28]. HexA was found as a major acidic substituent in kraft pulp, covering over $83 \%$ of the total residual uronic acids [29]. Due to its unsaturated nature, the HexA was shown to act as carbohydrate-derived chromophore, detrimentally affecting optical properties of bleached pulps, i.e., decreasing brightness and increasing brightness reversion [30]. Quantification of HexA has therefore a direct practical interest and importance for pulp bleaching. Ozone, as a strong electrophile, reacts readily with HexA and causes HexA degradation by about $68 \%$ in control eucalypt kraft pulp (Table 1). The presence of POM inhibits HexA degradation. The mentioned POMs capacity to suppress radical-induced (ozone-based) reactions is a most probable reason of increased HexA content in POM/water ozonated pulp. The HexA content in $\mathrm{POM} /$ solvent media is somewhat lower. Considering the extremely low stability of HexA towards acidic reaction conditions [28], such as occurring in pulp ozonation, the higher acidic activity of solventbased reaction solutions can partially explain the additional HexA losses (due to acid-catalyzed solvolytic degradation) in comparison with aqueous (POM/water) media.

As shown in Fig. 4, strong positive correlations can be observed between brightness improvement during POM-catalyzed ozonation of eucalypt kraft pulp in organic solvents and lignin and, particularly, HexA removal $\left(R^{2}=0.911\right.$ and $R^{2}=0.951$, respectively). This pointed to the significance of carbohydrate-derived chromophores (beside the lignin-based ones) in brightness development of chemical pulps in the chosen bleaching system.
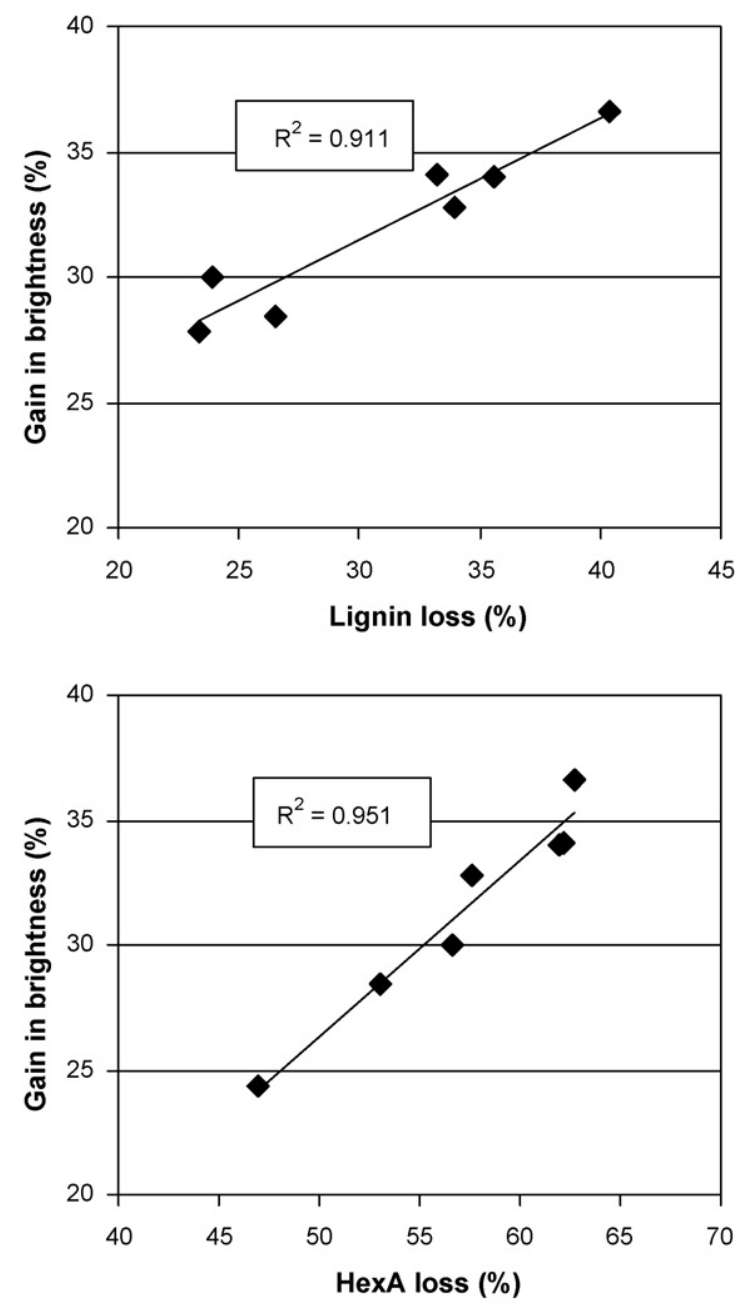

Fig. 4. Gain in brightness as a function of lignin (top) and HexA (bottom) loss during POM-catalyzed pulp ozonation in various organic solvents. Ozonation conditions: $3 \%$ pulp consistency; $\left[\mathrm{O}_{3}\right]=0.8 \%$ odp; $[\mathrm{HPA}-5]=0.5 \mathrm{mM} ; 6 \%(\mathrm{w} / \mathrm{w})$ solvent concentration; $\mathrm{pH}=2$.

To underline the catalytic effect of POM, the catalyst-free pulp ozonation in organic solvents have been carried out using ethanol-water solution (proved to be beneficial for ozone bleaching [18]) as a reaction media (see water/ethanol in Table 1). Similar to previously reported data [18], the addition of ethanol (6\%, $\mathrm{w} / \mathrm{w}$ ) reduced carbohydrate degradation thereby increasing pulp intrinsic viscosity, but only slightly effected pulp delignification and brightness in comparison with control (water) ozonation. The introduction of POM catalyst substantially improved efficiency and selectivity of ozonation (see POM/water/ethanol in Table 1). The notable increase in pulp brightness (by $1.6 \%$ ISO), degree of delignification (by $12 \%$ ) and pulp viscosity (by $4 \%$ ) was observed in comparison with non-catalyzed ethanol-water system, pointing to decisive role (contribution) of catalyst for successful pulp ozonation.

\subsection{POM-catalyzed ozonation in acetone/water solution}

Based on the results of solvent screening experiments, the acetone-water reaction media was chosen for further studies of POM-catalyzed ozonation. The effect of solvent content and catalyst concentration was examined.

As shown in Figs. 5 and 6 (top), the progressive increase in solvent proportion in the reaction mixture causes impressive increases in pulp brightness and delignification. A brightness gain by $11.6 \%$ 

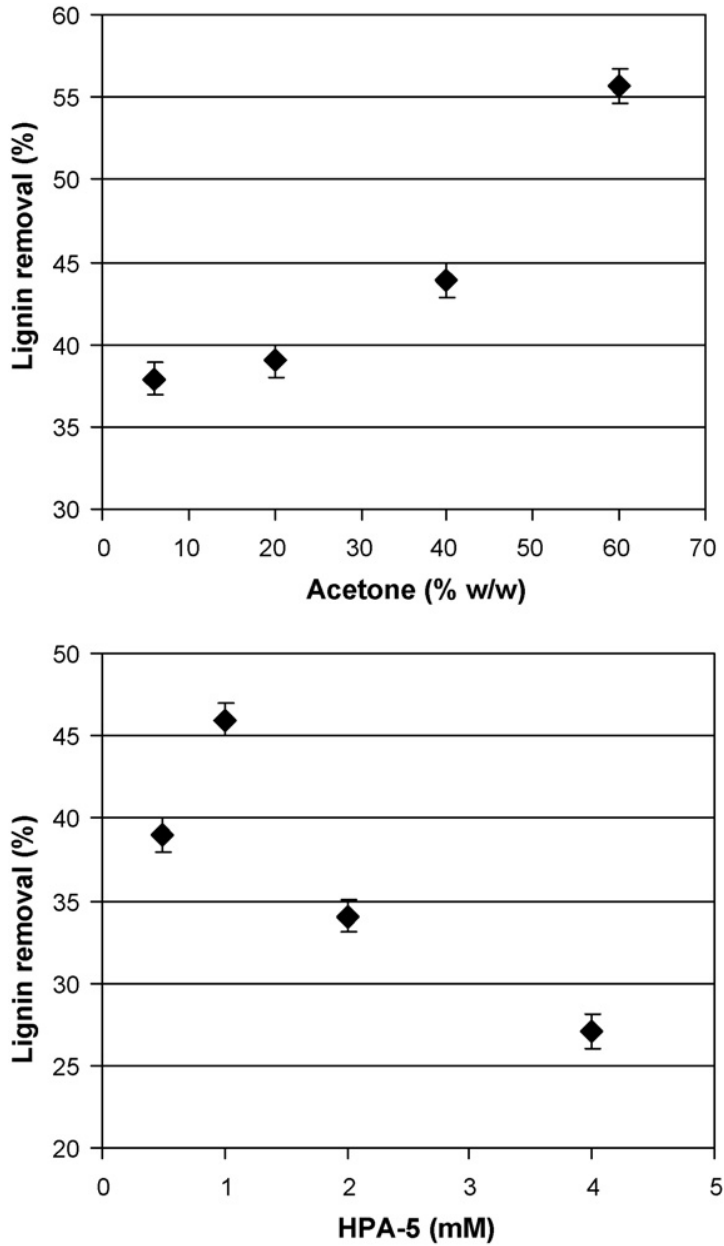

Fig. 5. Effect of organic solvent content (top) and POM concentration (bottom) on lignin removal during pulp ozonation. Ozonation conditions: $[\mathrm{HPA}-5]=0.5 \mathrm{mM} ; 3 \%$ pulp consistency; $\left[\mathrm{O}_{3}\right]=0.8 \%$; $\mathrm{pH}=2$ (top) and $20 \%(\mathrm{w} / \mathrm{w}$ ) of solvent; $3 \%$ pulp consistency; $\left[\mathrm{O}_{3}\right]=0.8 \% ; \mathrm{pH}=2$ (bottom). Error bars represent the standard deviation of three replicates.

ISO and additional lignin removal by $17.8 \%$ was observed with a rise in solvent content in the reaction mixture from $6 \%$ to $60 \%$ $(\mathrm{w} / \mathrm{w})$, offering substantial bleaching improvement (by $15.1 \%$ and $39.4 \%$, respectively, for brightening and delignification) in comparison with POM/water ozonation. The accelerated intensity of bleaching reactions was particularly notable when solvent proportion exceeded $40 \%(\mathrm{w} / \mathrm{w})$, pointing to marginal concentration of organic solvent in the reaction solution for successful pulp ozonation.

It is evident from Fig. 7 (top) that the increase in solvent content up to $40 \%(\mathrm{w} / \mathrm{w})$ has favorable effect on carbohydrates, increasing pulp intrinsic viscosity and thereby improving selectivity of ozonation as a whole in comparison with aqueous solution, as a result of scavenging by solvent of active oxygen-centered radical species formed during ozonation. The content of $\mathrm{CHO}$ groups in ozonated pulps decreases directly $\left(R^{2}=0.97\right)$ with increase in solvent proportion in the bleaching solution (Fig. 8, top) thereby confirming the effective suppression of oxidative degradation reactions. The further increase in solvent concentration causes a substantial drop in pulp viscosity, indicating intensive polysaccharide degradation. A similar effect was also observed during HPA-catalyzed oxygen delignification in ethanol/water medium and was partially associated with increased intensity of acid-catalyzed (solvolytic) degradation processes under high organic solvent concentrations [11].
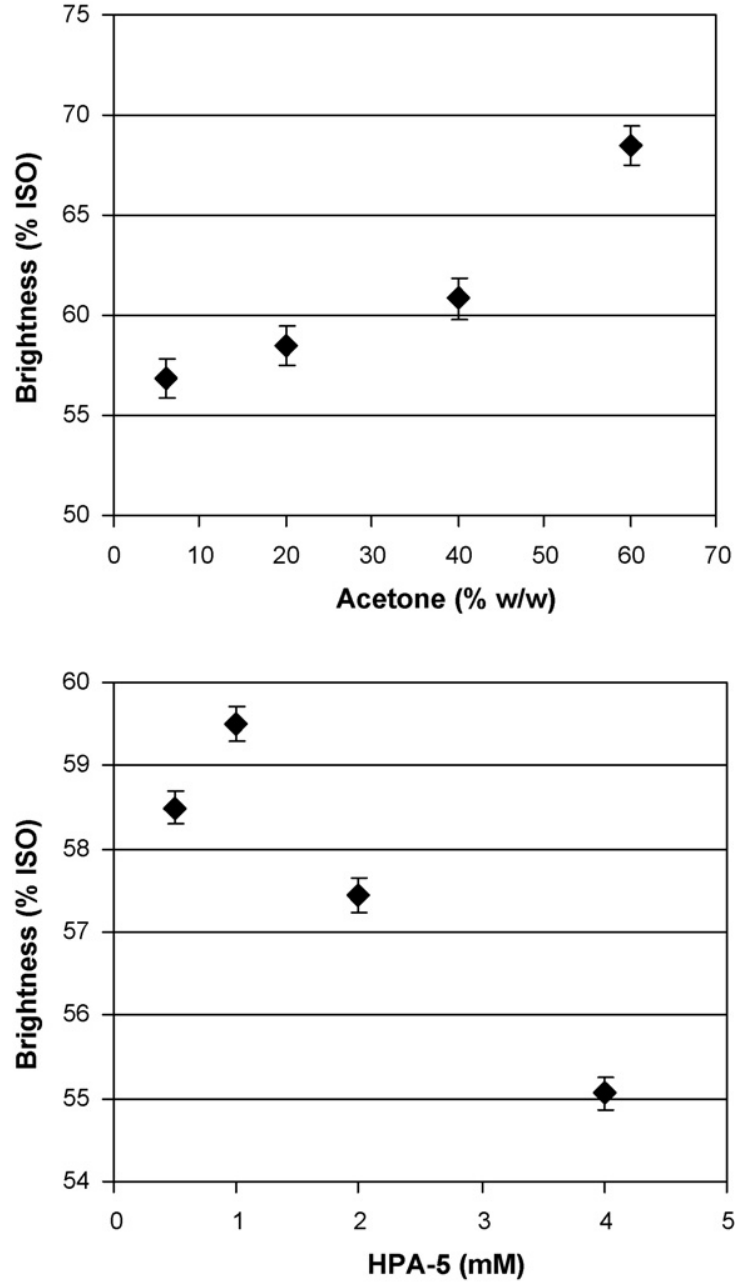

Fig. 6. Effect of organic solvent content (top) and POM concentration (bottom) on brightness development during pulp ozonation. Ozonation conditions: [HPA$5]=0.5 \mathrm{mM} ; 3 \%$ pulp consistency; $\left[\mathrm{O}_{3}\right]=0.8 \% ; \mathrm{pH}=2$ (top) and $20 \%(\mathrm{w} / \mathrm{w}$ ) of solvent $3 \%$ pulp consistency; $\left[\mathrm{O}_{3}\right]=0.8 \% ; \mathrm{pH}=2$ (bottom). Error bars represent the standard deviation of three replicates.

The effect of POM concentration on the course of ozonation reactions is illustrated in Figs. 5-7 (bottom). It can be seen that the maximal efficiency of POM-catalyzed ozonation in acetone media, i.e., the maximal catalytic effect of POM on ozone bleaching, can be achieved with a catalyst concentration of $1 \mathrm{mM}$. The additional lignin removal (by 7\%) and brightness improvement (by 1\% ISO) was noted with change in POM concentration from $0.5 \mathrm{mM}$ to $1 \mathrm{mM}$ (under fixed acetone content of $20 \%(\mathrm{w} / \mathrm{w})$ ). The subsequent increase in catalyst concentration up to $4 \mathrm{mM}$ led to a considerable drop in pulp delignification and brightening thus greatly decreasing the efficiency of ozonation as a whole. The enhanced ozone reactivity at $1 \mathrm{mM}$ POM was also confirmed by analysis of $\mathrm{CHO}$ groups in ozonated pulps (Fig. 8, bottom). The maximal degree of pulp oxidation (the highest $\mathrm{CHO}$ content) found at $1 \mathrm{mM}$ POM pointed to maximal intensity of oxidative bleaching reactions under this catalyst concentration. The remarkable agreement in the POMdepending bleaching profiles of $\mathrm{CHO}$ groups, lignin removal and brightness improvement was observed, underlining the significance of catalyst concentration for effective pulp ozonation.

The intrinsic viscosity of pulps ozonated in acetone solution continuously increases with a rise in catalyst concentration from $0.5 \mathrm{mM}$ to $4 \mathrm{mM}$ (Fig. 7, bottom). A small "shoulder", easily noticed in the plot at $1 \mathrm{mM}$ POM, is a result of the above-mentioned elevated oxidation (or oxidative degradation) of ozonated pulps under this 

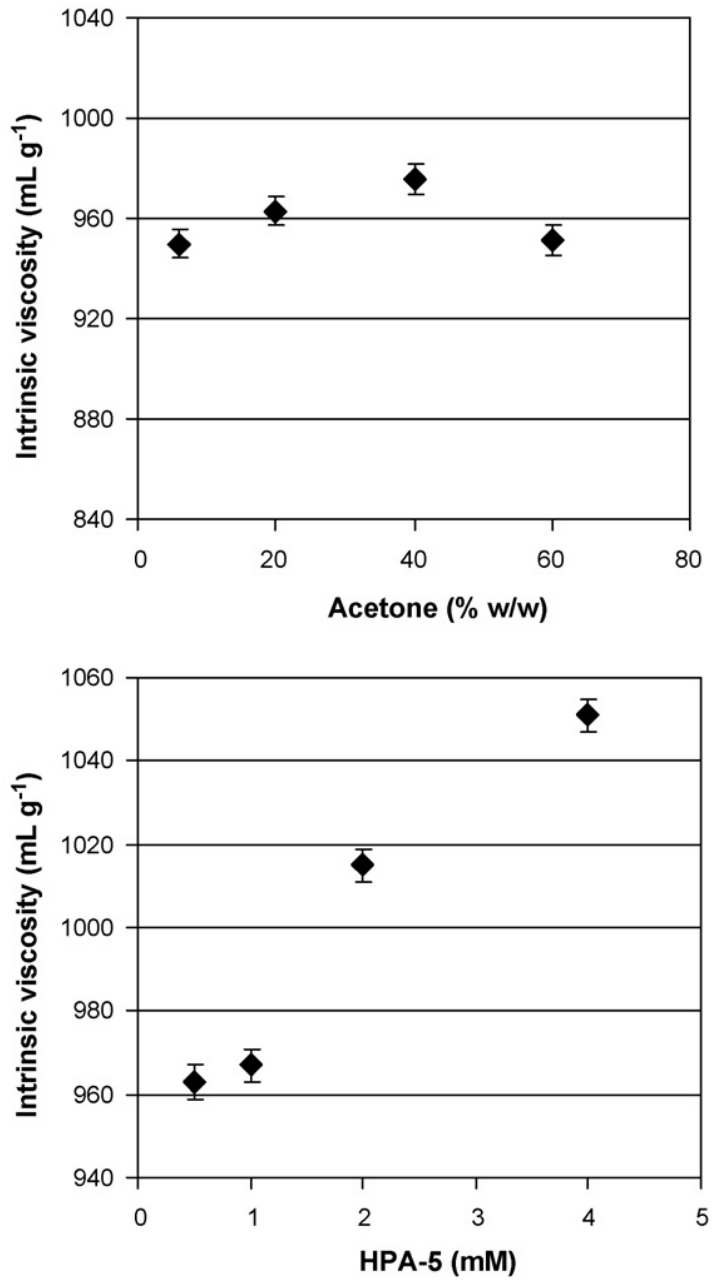

Fig. 7. Effect of organic solvent content (top) and POM concentration (bottom) on intrinsic viscosity of ozonated pulps. Ozonation conditions: [HPA-5] $=0.5 \mathrm{mM} ; 3 \%$ pulp consistency; $\left[\mathrm{O}_{3}\right]=0.8 \%$; $\mathrm{pH}=2$ (top) and $20 \%(\mathrm{w} / \mathrm{w})$ of solvent; $3 \%$ pulp consistency; $\left[\mathrm{O}_{3}\right]=0.8 \% ; \mathrm{pH}=2$ (bottom). Error bars represent the standard deviation of three replicates.

marginal catalyst concentration. Nevertheless, the change in viscosity at $1 \mathrm{mM}$ POM is not so appreciable and keeps the general tendency on viscosity improvement.

The change in solvent and catalyst concentration has no essential effect on the physical (mechanical) properties of ozonated pulps (Table 2). The minimal changes in bursting and tearing pulp strength are within the range of standard deviation and have no statistical significance. At the same time, it is clear that the tensile strength of ozonated pulps is better under higher solvent and lower POM concentrations, evidently being related to the degree of pulp delignification under these ozonation conditions.
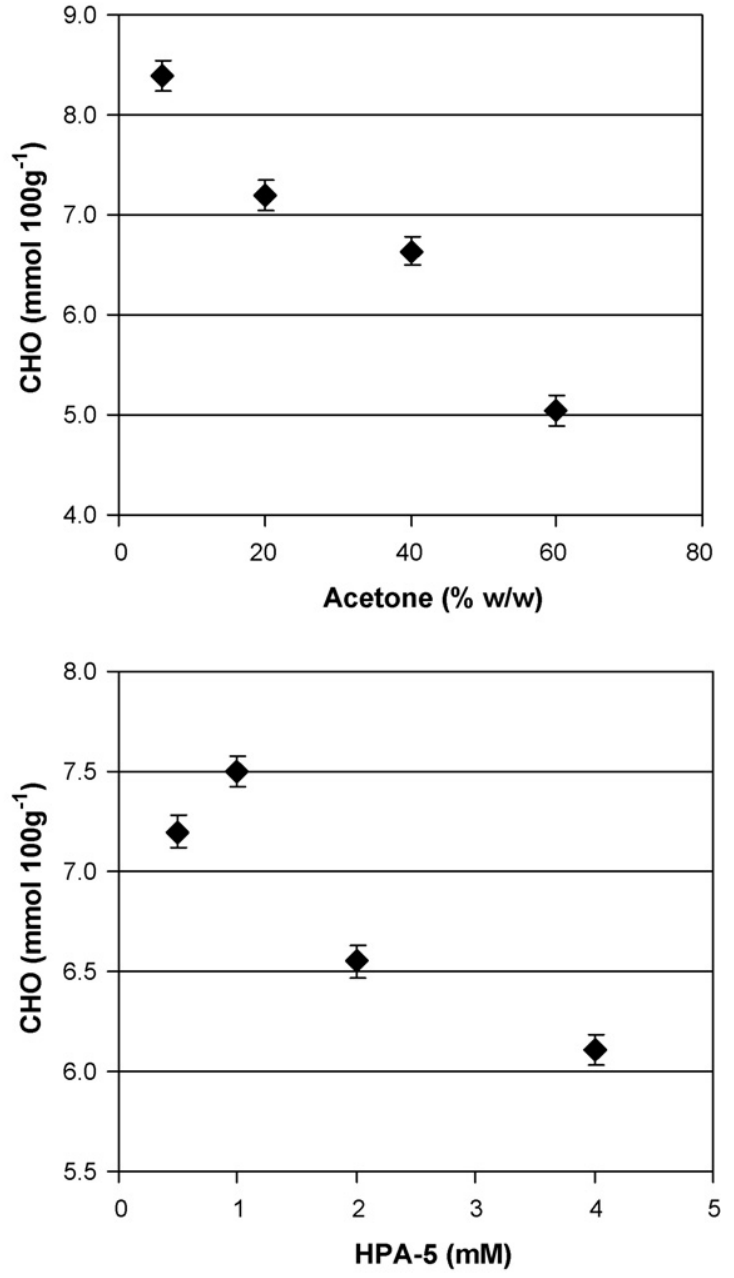

Fig. 8. Effect of organic solvent content (top) and POM concentration (bottom) on content of aldehyde ( $\mathrm{CHO}$ ) groups in ozonated pulps (expressed as mmol of $\mathrm{CHO}$ groups per $100 \mathrm{~g}$ of oven-dry pulp). Ozonation conditions: [HPA-5] $=0.5 \mathrm{mM} ; 3 \%$ pulp consistency; $\left[\mathrm{O}_{3}\right]=0.8 \% ; \mathrm{pH}=2$ (top) and $20 \%(\mathrm{w} / \mathrm{w}$ ) of solvent; $3 \%$ pulp consistency; $\left[\mathrm{O}_{3}\right]=0.8 \% ; \mathrm{pH}=2$ (bottom). Error bars represent the standard deviation of three replicates.

\section{Discussion}

The catalytic effect of mixed-addenda heteropolyoxovanadomolybdates as reversible oxidants in liquid-phase oxidation electron transfer or redox type oxidations is commonly expressed by the simplified reaction scheme [31]:

Substrate $+\mathrm{POM}_{\mathrm{ox}} \rightarrow$ Substrate $_{\mathrm{ox}}+\mathrm{POM}_{\mathrm{red}}$

$\mathrm{POM}_{\text {red }}+$ Oxidant $\rightarrow \mathrm{POM}_{\mathrm{Ox}}$

where $\mathrm{POM}_{\mathrm{Ox}}$ and $\mathrm{POM}_{\mathrm{red}}$ are the oxidized and reduced forms of POM, respectively; Substrate $_{\text {ox }}$ is the oxidized form of substrate and

Table 2

Effect of solvent content and catalyst (POM) concentration on physical properties of ozonated eucalypt kraft pulp $\left(\mathrm{O}_{3}\right.$ charge $0.8 \%$ on oven-dry pulp; pH = 2).

\begin{tabular}{|c|c|c|c|}
\hline Ozonation conditions & Tensile index $(\mathrm{N} \mathrm{m} / \mathrm{g})$ & Burst index $\left(\mathrm{kPa} \mathrm{m}^{2} / \mathrm{g}\right)$ & Tear index $\left(\mathrm{mN} \mathrm{m}^{2} / \mathrm{g}\right)$ \\
\hline Acetone $6 \%(\mathrm{w} / \mathrm{w}) ;[\mathrm{HPA}-5]=0.5 \mathrm{mM}$ & $4.58 \pm 0.12$ & $0.18 \pm 0.03$ & $4.16 \pm 0.11$ \\
\hline Acetone $20 \%(\mathrm{w} / \mathrm{w}) ;[\mathrm{HPA}-5]=0.5 \mathrm{mM}$ & $4.83 \pm 0.08$ & $0.19 \pm 0.02$ & $3.95 \pm 0.09$ \\
\hline Acetone $40 \%(\mathrm{w} / \mathrm{w}) ;[\mathrm{HPA}-5]=0.5 \mathrm{mM}$ & $5.75 \pm 0.05$ & $0.22 \pm 0.01$ & $3.91 \pm 0.10$ \\
\hline Acetone $60 \%(\mathrm{w} / \mathrm{w}) ;[\mathrm{HPA}-5]=0.5 \mathrm{mM}$ & $6.09 \pm 0.10$ & $0.22 \pm 0.02$ & $4.09 \pm 0.09$ \\
\hline [0.5 mM HPA-5]; acetone $20 \%(\mathrm{w} / \mathrm{w})$ & $4.83 \pm 0.06$ & $0.19 \pm 0.03$ & $3.95 \pm 0.07$ \\
\hline [1.0 mM HPA-5]; acetone $20 \%$ (w/w) & $4.64 \pm 0.05$ & $0.20 \pm 0.01$ & $3.86 \pm 0.09$ \\
\hline [2.0 mM HPA-5]; acetone $20 \%(\mathrm{w} / \mathrm{w})$ & $4.24 \pm 0.07$ & $0.21 \pm 0.01$ & $3.62 \pm 0.06$ \\
\hline [4.0 mM HPA-5]; acetone $20 \%(\mathrm{w} / \mathrm{w})$ & $4.01 \pm 0.05$ & $0.23 \pm 0.02$ & $3.79 \pm 0.08$ \\
\hline
\end{tabular}


Oxidant is $\mathrm{O}_{2}, \mathrm{O}_{3}$ or $\mathrm{H}_{2} \mathrm{O}_{2}$. The oxidation of organic substrates occurs due to the ability of $\mathrm{V}(\mathrm{V})$ to accept electrons from the substrate. The reduced $V(I V)$ can be oxidized back to $V(V)$ via reaction with appropriate oxidant, closing thereby the redox cycle by catalyst. Thus, the HPA of series $\left[\mathrm{PMo}_{(12-n)} \mathrm{V}_{n} \mathrm{O}_{40}\right]^{(3+n)-}$ with $n>1$ have the property of easy reversible multi-electron oxidants [32].

During one-stage POM-oxidation (the case of the present study), both reaction steps, i.e., stoichiometric oxidation of the substrate (1) and re-oxidation of the reduced form of the catalyst (2), take place simultaneously. The thermodynamic condition for POM (HPA5) catalyzed pulp bleaching (or, basically, delignification) by ozone is the following:

$E^{\mathrm{O}}($ Lignin $)<E^{\mathrm{O}}(\mathrm{POM})<E^{\mathrm{O}}\left(\mathrm{O}_{3}\right)$

where $E^{\mathrm{o}}$ (Lignin), $E^{\mathrm{o}}(\mathrm{POM})$ and $E^{\mathrm{o}}\left(\mathrm{O}_{3}\right)$ are the oxidation potentials, respectively, of lignin (0.4-0.6 eV vs. NHE at $\mathrm{pH} 1)$ [33], HPA (0.68-0.71 eV vs. NHE at $\mathrm{pH} 1$ ) [34] and ozone (2.07 eV at pH 2) [16].

The bleaching efficiency of POMs (reaction step (1)) is therefore completely controlled by intensity (or efficiency) of POMs regeneration along the bleaching (reaction step (2)). Considering the better ozone solubility in organic solvents (under the same physical conditions, i.e., temperature and ozone partial pressure, the ratio of equilibrium ozone concentration in organic solvent and in water is about 10 [35], as a result of reduced interfacial tension of the liquid phase leading to facilitated ozone mass transfer to the solvent solution [20]), the increased delignification rate in organic solvents is a result of higher concentration of active (dissolved) ozone in the reaction mixture and increased therefore intensity of catalyst re-oxidation (regeneration) during ozonation. Obviously, the concentration of dissolved ozone is directly related to solvent proportion in solution explaining thereby substantial acceleration of ozonation bleaching activity observed under elevated solvent (acetone) concentrations.

The enhanced solubility of lignin (or lignin degradation products) in organic solvents can also contribute to better pulp delignification during solvent-assisted ozonation in comparison with water [36]. The dissolution effect varies for different solvents and depends on their hydrogen-bonding capacity ( $\delta$-value), which normally increases in solvent mixtures with water [37]. At the same time, it was reported that the addition of ethanol has no effect on ozone delignification (i.e., lignin removal) of kraft pulp [18], presumably because of high degree of molecule association in alcohols that decreases the solvent capacity for lignin solubilization [37].

The remarkable concentration's dependence of HPA- 5 catalytic activity is a result of structural and redox changes of the catalyst in the reaction solution under ozonation conditions. In diluted acid solutions the HPAs suffer degradative dissociation with formation of defect (lacunary) heteropoly species and release of $\mathrm{VO}_{2}{ }^{+}$ions [3]. These latter, having higher oxidation potential than the parent HPA $(0.87 \mathrm{~V}$ vs. $0.71 \mathrm{~V}, \mathrm{pH} 1)$ [38], were shown to be the principal active species in oxidation of the phenolic model compounds [39] and cellulose [11]. The HPA resistance to dissociation increases in concentrated solutions [3]. Thus, the highest rate of ozone delignification observed in $1 \mathrm{mM}$ HPA- 5 solution is associated with maximal release of $\mathrm{VO}_{2}{ }^{+}$ions from the coordination sphere of POM. The further increase in HPA-5 concentration retards its dissociation and lowers the content of free $\mathrm{VO}_{2}{ }^{+}$ions in solution, what in its turn causes decrease in pulp delignification and brightening, as well. An excellent correlation $\left(R^{2}=0.993\right)$ was found between gain in brightness and lignin removal pointing to the important role of lignin-derived chromophores.

The limited dissociation of HPA-5 and reduced release of $\mathrm{VO}_{2}{ }^{+}$ ions is an obvious reason of the observed increase in intrinsic viscosity of pulps ozonated under elevated catalyst concentrations. The suppression of polysaccharide degradation leads to viscosity improvement up to $9.1 \%$ with change in POM concentration in reac- tion solution from $0.5 \mathrm{mM}$ to $4.0 \mathrm{mM}$. Contrary to the expectations, no appreciable drop in pulp viscosity was noted under a critical catalyst concentration of $1 \mathrm{mM}$, confirming the protective effect of organic solvent against oxidative degradation of carbohydrates.

The practical (commercial) feasibility of the proposed bleaching approach will be obviously depending on the costs/efficiency of chemicals recovery and, consequently, on the environmental impact of this technology. The totally effluent-free (TEF) concept of POM bleaching with repeated recirculation of the reaction solution can minimize any catalyst and solvent losses with the liquid process streams after pulp ozonation, meeting thereby the economical and ecological concerns related to chemical recovery. The risk of catalyst (heavy metals) retention in bleached pulp can be excluded by efficient pulp washing after POM stage, as it was shown by pilot-plant experiments on POM promoted oxygen delignification [40]. Some inevitable solvent vapors formed, e.g., during liquor preparation before reuse in the next ozonation cycle, can be easily recycled back by simple condensation without significant increase in bleaching costs.

The distribution of ionic species in pulp suspension (Donnan effect) and its influence on mechanism of POM re-oxidation and pulp delignification under applied ozonation conditions still need to be studied, to find the ways for further process improvement. These studies are currently under progress in our research group.

\section{Conclusions}

A novel particularly effective and selective approach of POMcatalyzed ozone bleaching of chemical pulps using organic solvents as a reaction media has been developed. A series of organic solvents were shown to have a well-defined capacity for ozonation improvement in the presence of Keggin-type mixed-addenda molybdovanadophosphate heteropolyanion HPA-5. The maximal bleaching effect (the highest pulp brightening and delignification) was observed in aqueous acetone solution. Under optimized conditions, the POM-catalyzed ozonation of industrial eucalypt kraft pulp in acetone/water media showed a brightness improvement by $15.1 \%$ ISO with an additional lignin removal by $39.4 \%$ and an increase in intrinsic viscosity by $3 \%$ in comparison with conventional ozonation in water media.

\section{Acknowledgement}

The financial support of the Fundação para a Ciência e a Tecnologia (FCT, Portugal) is gratefully acknowledged.

\section{References}

[1] M.T. Pope, Heteropoly and Isopoly Oxometalates, Springer-Verlag, New York, 1983.

[2] C.L. Hill, C.M. Prosser-McCartha, Homogeneous catalysis by transition metal oxygen anion clusters, Coord. Chem. Rev. 143 (1995) 407-455.

[3] I.V. Kozhevnikov, K.I. Matveev, Homogeneous catalysts based on heteropoly acids, Appl. Catal. A 5 (1983) 135-150.

[4] Y. Ono, Heteropoly acid catalysis-a unique blend of acid-base and redox properties, in: J.M. Thomas, K.I. Zamarev (Eds.), Perspectives in Catalysis, Blackwell Sci. Publ., Oxford, 1992, pp. 431-464.

[5] N. Mizuno, M. Misono, Heteropolyanions in catalysis, J. Mol. Catal. 86 (1994) 319-342.

[6] I.A. Weinstock, R.H. Atalla, R.S. Reiner, M.A. Moen, K.E. Hammel, C.J. Houtman, C.L. Hill, A new environmentally benign technology and approach to bleaching kraft pulp. Polyoxometalates for selective delignification and waste mineralization, New J. Chem. 20 (1996) 269-275.

[7] D.V. Evtuguin, C.P. Neto, J.D. Pedrosa de Jesus, Bleaching of kraft pulp by oxygen in the presence of polyoxometalates, J. Pulp Pap. Sci. 24 (1998) 133-139.

[8] M.L. Bianchi, R. Crisol, U. Schuchardt, Bleaching of commercial pulps with $\mathrm{H}_{2} \mathrm{O}_{2}$ catalyzed by heteropolyanions, Bioresour. Technol. 68 (1999) 17-21.

[9] A.R. Gaspar, J.A.F. Gamelas, D.V. Evtuguin, C.P. Neto, Alternatives for lignocellulosic pulp delignification using polyoxometalates and oxygen: a review, Green Chem. 9 (2007) 717-730. 
[10] A.A. Shatalov, D.V. Evtuguin, C. Pascoal Neto, Cellulose behaviour in molybdovanadophosphate heteropolyanions catalysed aerobic oxidation, in: 5th European Workshop on Lignocellulosics and Pulp, Aveiro, Portugal, 1998, pp. 353-356.

[11] A.A. Shatalov, D.V. Evtuguin, C. Pascoal Neto, Cellulose degradation in the reaction system $\mathrm{O}_{2} /$ heteropolyanions of series $\left[\mathrm{PMo}_{(12-n)} \mathrm{V}_{n} \mathrm{O}_{40}\right]^{(3+n)-}$, Carbohydr Polym. 43 (2000) 23-32.

[12] B. Van Lierop, A. Skothos, N. Liebergott, Ozone delignification, in: C.W. Dence, D.W. Reeve (Eds.), Pulp Bleaching. Principles and Practice, Tappi Press, Atlanta, 1996, pp. 321-345.

[13] M.V. Byrd Jr., J.S. Gratzl, R.P. Singh, Delignification and bleaching of chemical pulps with ozone: a literature review, Tappi J. 75 (1992) 207-213.

[14] M. Bokstrom, A. Tuomi, Interest in applying ozone is growing, Paperi Ja Puu Paper and Timber 83 (2001) 124-127.

[15] J.E. King, A.R.P. Van Heiningen, Effect of pulp species and pretreatment on the rates of delignification and cellulose degradation during ozone bleaching, Pulp Paper - Canada 104 (2003) 38-42.

[16] R.C. Rice, A. Netzer, Handbook of Ozone Technology and Application, Ann Arbor Science Publishers, Ann Arbor, 1982.

[17] K. Kamishima, T. Fujii, I. Akkatsu, Ozone bleaching of kraft pulp with addition of methanol as cellulose protector, Japan Tappi 31 (1977) 699-706.

[18] Y. Ni, A.R.P. Van Heiningen, J. Lora, L. Magdzinski, E.K. Pye, A novel ozone bleaching technology for the ALCELL process, J. Wood Chem. Technol. 16 (1996) 367-380.

[19] B. Saake, R. Lehnen, E. Schmekal, A. Neubauer, H.H. Nimz, Bleaching of Formacell pulp from aspen wood with ozone and peracetic acid in organic solvents, Holzforschung 52 (1998) 643-650.

[20] E. Cogo, J. Albert, G. Malmary, C. Coste, J. Molinier, Effect of reaction medium on ozone mass transfer and applications to pulp bleaching, Chem. Eng. J. 73 (1999) 23-28.

[21] K.I. Matveev, N.B. Shitova, Z.P. Pai, V.F. Odyakov, O.K. Akmalova, L.I. Kuznetsova, T.A. Basalaeva, A.B. Rumiantsev, L.N. Shadrin, SU Patent 421226 (1972) Int. C1. B $01 \mathrm{~J} 37 / 04$

[22] A.V. Obolenskaya, Z.P. Elnitskaya, A.A. Leonovitch, Laboratory practicum on wood and cellulose chemistry, Ecology, Moscow, 1991, pp. 211-212.

[23] T.Vuorinen, P. Fagerström, J. Buchert, M. Tenkanen, A. Teleman, Selective hydrolysis of hexenuronic acid groups and its application in ECF and TCF bleaching of kraft pulps, J. Pulp Pap. Sci. 25 (1999) 155-162.

[24] Y. Zhang, G. Kang, Y. Ni, A.R.P. Van Heiningen, Degradation of wood polysaccharide model compounds during ozone treatment, J. Pulp Pap. Sci. 23 (1997) J23-J27.

[25] J. Staehelln, J. Hoigné, Decomposition of ozone in water in the presence of organic solutes acting as promoters and inhibitors of radical chain reactions, Environ. Sci. Technol. 19 (1985) 1206-1213.
[26] S. Chandra, J.S. Gratzl, Kinetics of carbohydrate and lignin degradation and formation of carbonyl and carboxyl groups in low consistency ozonation of softwood pulps, in: Int. Pulp Bleaching Conference, CPPA, Quebec, Montreal, Canada, 1985, pp. 27-30.

[27] I.V. Kozhevnikov, Catalysis by heteropoly acids and multicomponent polyoxometalates in liquid-phase reactions, Chem. Rev. 98 (1998) 171-198.

[28] M.H. Johansson, O. Samuelson, Epimerization and degradation of 2-O(4-O-methyl- $\alpha$-D-glucopyranosyluronic acid)-D-xylitol in alkaline medium, Carbohydr. Res. 54 (1977) 295-299.

[29] J. Buchert, A. Teleman, V. Harjunpää, M. Tenkanen, L. Viikari, T. Vuorinen, Effect of cooking and bleaching on the structure of xylan in conventional pine kraft pulp, Tappi J. 78 (1995) 125-130.

[30] J. Buchert, E. Bergnor, G. Lindblad, L. Viikari, M. Ek, Significance of xylan and glucomannan in the brightness reversion of kraft pulps, Tappi J. 80 (1997) 165-171.

[31] M.T. Pope, A. Muller, Polyoxometalate chemistry: an old field with new dimensions in several disciplines, Angew. Chem. Int. Ed. Engl. 30 (1991) 34-48.

[32] I.V. Kozhevnikov, K.I. Matveev, Heteropolyacids in catalysis, Russ. Chem. Rev. 51 (1982) 1075-1088.

[33] I.A. Weinstock, R.H. Attala, R.S. Reiner, M.A. Moen, K.E. Hammel, C.J. Houtman, C.L. Hill, M.K. Harrup, A new environmentally benign technology for transformation wood pulp into paper. Engineering polyoxometalates as catalysts for multiple processes, J. Mol. Catal. A: Chem. 116 (1997) 59-84.

[34] V.F. Odyakov, E.G. Zhizhina, K.I. Matveev, Redox potentials of molybdovanadophosphoric heteropoly acids in aqueous solutions, J. Mol. Catal. A: Chem. 158 (2000) 453-456.

[35] A.K. Bin, Ozone solubility in liquids, Ozone: Sci. Eng. 28 (2006) 67-75.

[36] J. Quesada, M. Rubio, D. Gomes, Lignin organosolvolysis from autohydrolyzed corn (Zea mays) stalks: ozonation of both solvolytic solid and juice, J. Appl. Polym. Sci. 68 (1998) 1867-1876.

[37] C. Schuerch, The solvent properties of liquids and their relation to the solubility, swelling, isolation and fractionation of lignin, J. Am. Chem. Soc. 74 (1952) 5061-5067.

[38] I.V. Kozhevnikov, $\mathrm{PMo}_{12-n} \mathrm{~V}_{n} \mathrm{O}_{40}{ }^{(3+n)-}$ heteropolyanions as catalysts for aerobic oxidation, J. Mol. Catal. 117 (1997) 151-158.

[39] O.A. Kholdeeva, A.V. Golovin, R.I. Maksimovskaya, I.V. Kozhevnikov, Oxidation of 2,3,6-trimethyl-phenol in the molybdovanadophosphoric heteropoly acids, J. Mol. Catal. 75 (1992) 235-244.

[40] A. Gaspar, D.V. Evtuguin, C.P. Neto, Polyoxometalate-catalyzed oxygen delignification of kraft pulp: a pilot-plant experience, Ind. Eng. Chem. Res. 43 (2004) 7754-7761. 